\title{
Selection of Industrial Packaging System in Closed-loop Automotive Supply Chains
}

\author{
K. Vöröskőii ${ }^{1}$ P. Böröcz ${ }^{1}$ \\ ${ }^{1}$ Széchenyi István University, Department of Logistics and Forwarding \\ Egyetem tér 1., 9026 Győr, Hungary \\ E-mail: voroskoi.kata@sze.hu
}

Abstract: The corporate decisions in the field of packaging aim to find and determine the optimal packaging functions and expenses at the same time. One-way packaging is also used in the practice, but returnable packaging is more common in the outbound flow of the automotive engine manufacturer companies. In addition, it can happen that packaging devices originally designed for one way are used multiple times, because the technical condition of the packaging ensures the repeated usage and the other way around. Transport distance is an important aspect while choosing the right packaging system, but according to our investigation the ratio between the purchasing cost of a new device and the cost of backwards transportation should also influence this decision. Therefore, the scope of this paper is to give a model of the cost structure of returnable industrial packaging operating in a closed loop system. The total cost will be especially determined by the return ratio, cost of return transport and planned number of uses.

Keywords: returnable packaging; closed-loop; packaging cost

\section{Introduction}

The packaging design has a strategic impact on the efficiency of the supply chain (SC). Packaging links the entire supply chain and coordinates all participants in the process to give a flexible and effective response to customer needs in order to maximize satisfaction at optimal cost [1].

It has been found that paying limited attention to packaging can cause higher costs in the physical distribution. Furthermore, researchers argue that packaging should 
not only be considered from the cost point of view, but focus should be put on its role as a value-added function in the SC [2].

Nowadays packaging designers are increasingly focusing on balancing the need for product protection, material use efficiency and the packaging material's impact on the environment along the whole supply chain [3].

Sustainability (green supply chain and environmental aspects) is closely related to packaging decisions in supply chain management [4]. Svanes' decision support methodology for sustainable packaging design rather focuses on packaging optimisation than packaging minimisation. It offers a tool box, but one-way vs. returnable decision is not mentioned. Instead of traditional cost calculations total distribution costs of packed product are considered. It includes the cost of packaging materials, cost of packing process, cost of transport from the producer via the wholesaler to the retailer, costs of handling by users along the distribution chain and cost of product loss [5].

According to Dominic et al. a sustainable packaging development model needs three variables: technical, supply chain and environmental design. This also considers the whole supply chain from the beginning till the end, reverse processes included. However, reuse only appears in context of waste handling and reduction. Packaging cost is merely one of the numerous indicators as part of the business perspective. Because of the discussion of corrugated box packaging in this model, development of a returnable system is not addressed here. [4]

Other returnable packaging management models compare returnable packaging management strategies, the focus is on transportation cost and inventory holding cost, furthermore the division of these among the SC stakeholders. At the same time, they neglect for example procurement or management costs [6].

Therefore, in the field of logistic packaging (industrial transportation, or even consumer packaging) the companies make decisions in order to determine the optimal packaging expenses. This decision-making situation practically means a choice between the one-way and reusable (disposable or returnable) packaging systems [7]. It is significant in the decision making process that which costs and environmental effects the disposable packaging has. The construction of returnable packaging is usually more complex. Numerous factors appear and each of them should be examined separately and then all together. As returnable packaging is planned for multiple uses, packaging material should be usually stronger and the whole design has to handle excessive forces. 


\section{Theoretical framework for automotive packaging cost evaluation}

\subsection{Disposable vs. returnable packaging}

The best packaging solutions are those that can - beside the optimal cost levels maximize the use of packaging space so that all the products can easily be packed and stacked and at the same time reduce packaging waste [8]. Besides the support of logistics handling and containment, product and environmental protection is also one of the most important functions of packaging [9].

The following two types of packaging systems are mostly used in automotive industry: one-way and returnable. One-way packaging is only suitable for one use. Reusable containers are loaded with products and shipped to the destination, then the empty container is sent back to the same supplier, refilled with products and this cycle is repeated over and over again in a closed-loop. (Fig 1) In some cases it is an open-loop system, when reusable packaging is collected at a centralised return handling centre, where it is cleaned, stocked, and distributed for refilling. [10]

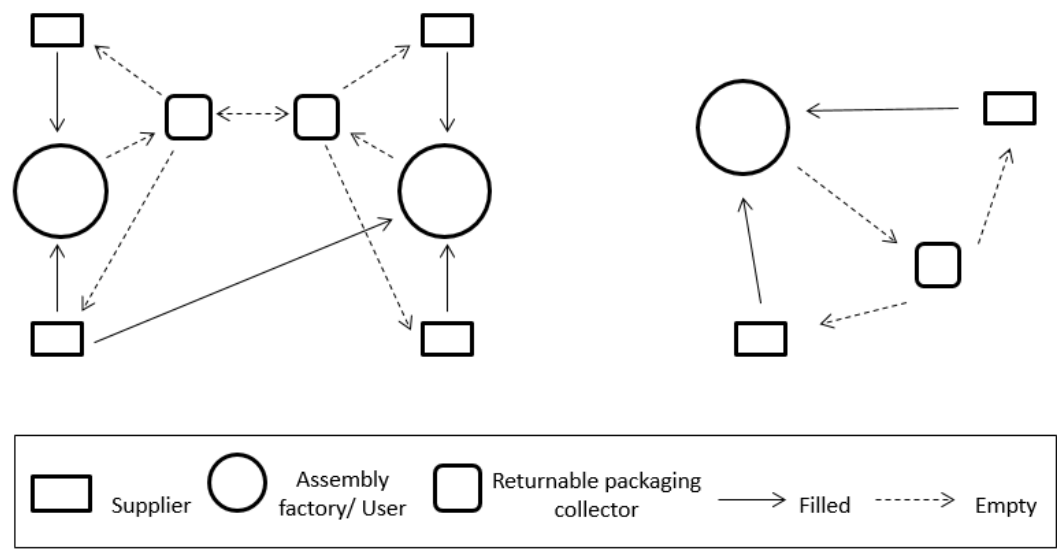

Figure 1. Open-loop (left) and closed-loop (right) returnable packaging system

The main problem with one-way packaging is the waste created after the usage, while relative production costs are lower. On the other hand, transportation and maintaining costs are a relevant issue in the case of returnable packaging [11].

In the automotive industry the primary function of packaging is the protection of products and parts optimised by the total costs of logistics [12]. This way, even if 
shipping is performed on land or sea, by rail, trucks, vessels or multi-mode shipping, the distribution environment and logistics costs together define the possible form of packaging, and then determine the final solution from disposable to returnable packaging and systems [13].

Returnable packaging has been frequently used, for example in the US automotive industry, in order to reduce waste, costs, transport damages and to enable JIT deliveries [14]. Standardised shipment materials are usually used as returnable packaging in the automotive supply chain (ASC), like the EUR/-EPAL pallets, racks, containers and specialty bins for certain types of parts [15].

The elimination of waste caused by disposable packaging is one of the main environmental factors to consider when choosing a returnable packaging system. Furthermore, returnable packages may contribute to a better workflow, because they are often easier to handle [16].

Legislation has also forced companies to rethink their packaging operations [17]. The green actions inclues green procurement, green manufacturing, green packaging, recycling and waste management to make the supply chain management more cost efficient and environmental friendly [18]. LCA (Life Cycle Assessment) is a commonly used method for defining and evaluating the total environmental load associated with a product, process or activity (or in this case packaging system), by identifying and quantifying energy and materials consumed and waste released into the environment. [19] [20]

Twede and Clark examined, which types of supply chains facilitate reusable packaging systems. They state that returnable packaging is not appropriate for every product or logistical system. The supply chains with short lead times and shipping distances, efficient sorting, cleaning and tracking systems and industry consortia for standardization are mainly suitable [21].

\subsection{Returnable packaging system costs}

Compared to disposable packages, returnable packages, because of their longer lifetime, can reduce the needed amount of packages, which can be more environmentally friendly. However, a returnable packaging system may have higher costs of procurement, transportation, and other costs caused by cleaning, repairing, storage and management, etc. [6] Therefore, introduction of a returnable packaging system does not always mean cost reduction. Although it may lead to significant savings in logistics cost in some cases, not all companies find this solution cost effective [22].

These decisions in the practice generally include only the purchase cost savings amortized over the reusable containers' lifetime and often do not include logistics 
costs. Nevertheless, the overall cost impact of such decisions remains unclear. A number of other factors affect the system cost, including the type of packaging used, transportation characteristics, handling, labour, and disposal costs. That is why the use of reusable containers does not always result in lower overall costs relative to disposable packaging because firm sourcing strategies and operations differ. [16]

\section{System elements of packaging cost}

In this section the total cost components and other factors of disposable and returnable packaging systems will be presented.

Table 1. Markings

\begin{tabular}{|l|}
\hline \multicolumn{1}{|c|}{ Markings } \\
\hline $\mathrm{CT}=$ total cost \\
\hline$\left(\mathrm{CT}_{\mathrm{D}}=\right.$ total cost of disposable packaging, $\mathrm{CT}_{\mathrm{R}}=$ total cost of returnable packaging $)$ \\
\hline $\mathrm{P}=$ price of the packaging device \\
\hline$\left(\mathrm{P}_{\mathrm{D}}=\right.$ price of disposable packaging, $\mathrm{P}_{\mathrm{R}}=$ price of returnable packaging $)$ \\
\hline $\mathrm{Q}=$ quantity \\
\hline $\mathrm{T}_{\mathrm{R}}=$ cost of return transport \\
\hline $\mathrm{U}=$ number of uses \\
\hline $\mathrm{S}=$ cost of storage \\
\hline $\mathrm{R}=$ repair cost \\
\hline $\mathrm{C}=$ cleaning cost \\
\hline $\mathrm{A}=$ administration cost \\
\hline $\mathrm{W}=$ cost of disposal/waste \\
\hline
\end{tabular}

\subsection{Packaging material cost}

Regarding returnable packaging systems, several studies suggest that they improve the impact of packaging on the environment, because they can reduce the amount of packaging material [12]. Within the environmental criterion of sustainable packaging design, six indicators are defined, two of them is related to packaging material:

- Gross material intensity, which covers the total amount of packaging materials used in the packaging system including reuse of five main types (fibre, plastic, glass, metal and wood). This parameter takes reuse into account. 
- Net material intensity describes the mass of packaging materials that are not being recycled, so it can be also seen as an estimate for the total amount of packaging waste generated from a logistics system. [5]

This cost can directly affect a company's returnable packaging system investment. Because of the improved product protection reusable containers can be even five to ten times more expensive in some cases than the disposable version that they replace [22].

In our case packaging material refers to purchasing price of the packaging devices, (all factors related to the production of the packaging are included in this component).

\subsection{Transport cost}

The transport costs can be divided into two parts: transport to the place of use and return transport. The cost for the return transport of empty containers can be mainly affected by the following factors:

- $\quad$ transport distance from the producer to the packaging collector where all the empty packages are gathered.

- possibility to take advantage of unbalance in transport flow, because of the use of joint loading when returning the packages.

- if the packaging is collapsible, it helps to maximize the amount of empty packaging for return transport. [16]

Transport is used in most parts of the ASC, but we examine the route between the engine producer and the buyer (the OEM). Since in our case study the cost of the first transport is the same for disposable or returnable packaging solutions (the destination is the same), only reverse transportation of the empty returnable packaging will be considered.

It was mentioned earlier that transport distance influences transport cost. Here we also have to mention the cycle time, which refers to the time a closed-loop is completed by the returnable packaging. In general, shorter cycle time may lead to lower initial investment cost, because less devices have to be purchased. Also shorter transportation distances usually result shorter cycle time. Nevertheless, to consider transport distance alone is not enough, complexity of the route and the supply chain has to be taken into consideration. Moreover, return transport opportunities and costs are even more important. 


\subsection{Administration, cleaning, repair and disposal (waste) cost}

Administration cost influences economics for both disposable and returnable packaging, but for returnable packaging also includes the management of the system, like related labour cost and cost of the information system. Cleaning and repair costs only appear in the case of reusable packaging in order to maintain the right condition of the packaging device. The use of returnable containers minimizes the disposal cost.

\subsection{Number of uses}

One-way packaging is only used once, but in the case of returnable ones the number of uses is a major issue. If we plan certain number of uses and the packaging devices can be only used less, because it is damaged due to for example inappropriate use, it will increase the total cost. It can also happen that the number of uses is beyond the originally planned number, in this case the total system cost can be decreased.

If disposable and returnable packaging should be compared in terms of usage ratio, it is logical to choose cheaper disposable packaging devices or more expensive returnable ones, which can be used as many times as possible. In this case a solution has to be found, where the goal of development is to maximize the number of uses. Nevertheless, the unexpected loss of returnable packaging may lead to great economic consequences.

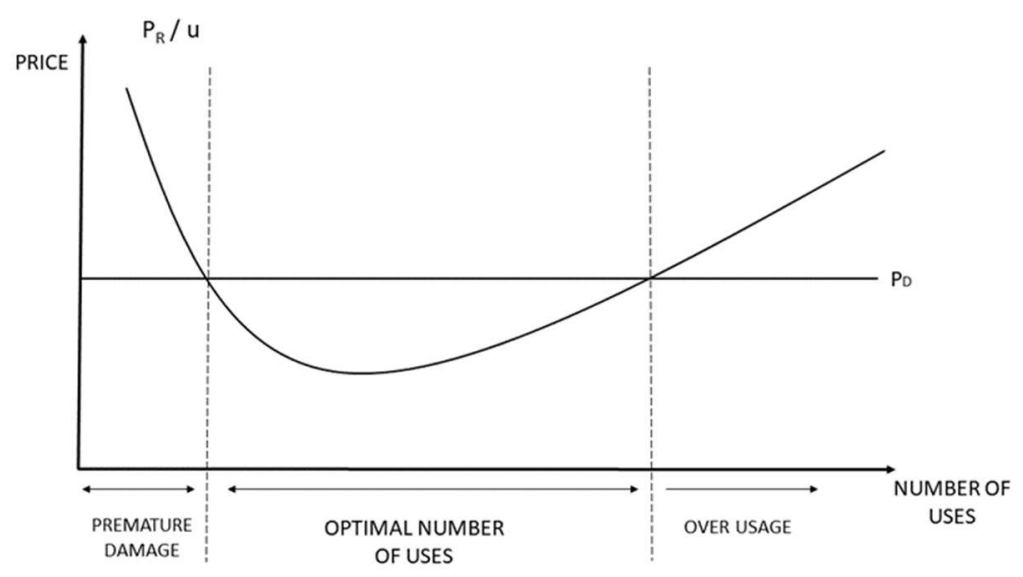

Figure 2. Usage ratio 
Fig 2 shows us how the number of uses influences the price of the packaging, compared to the price of the disposable solution. Three cases can occur:

- Premature damage: it can happen because the technical and mechanical properties of the chosen packaging are not appropriate or in case of an unexpected event (like for example damage because of inappropriate material handling or loss of the packaging device as described earlier).

- Optimal number of uses: the cost is optimal, when the planned number of uses is reached, even if the initial price of the returnable packaging is higher than the disposable version.

- Over usage: after the packaging exceeds the optimal number of uses, it can happen that the maintenance of the appropriate technical conditions of the packaging (repair cost) becomes more expensive and because of that the price is higher. Risk of damage can be also significantly higher in this phase.

\subsection{Packaging quantity}

It means the total number of packaging devices in use in a returnable packaging system or a number of disposable containers need to be purchased. It is strongly affected by the number of uses of a particular packaging device and the return ratio (described later) as well.

Mollenkopf et al conclude that packaging quantity increases should favour the use of reusable containers. In their cost model for reusable packaging they consider average daily volume and packaging quantity two of the most important factors [22]. Daily volume can also significantly influence the initial investment cost, as well as cycle time.

\section{An evaluation model for packaging cost structure}

\subsection{Cost of disposable packaging}

The determination of the final expenses (total cost) is effected by the following components in case of disposable (one-way) packaging:

- $\quad$ purchase price of the packaging device (packaging material cost)

- $\quad$ cost of storage 
- administration cost

- cost of disposal (waste).

$$
\sum C T_{D}=P_{D} Q+A_{D} Q+S_{D} Q+W_{D} Q
$$

where the total cost of disposable packaging $\left(\mathrm{CT}_{\mathrm{D}}\right)$ is calculated from the price of disposable packaging $\left(\mathrm{P}_{\mathrm{D}}\right)$, unit cost of administration $(\mathrm{A})$, storage $(\mathrm{S})$ and waste $(\mathrm{W})$ multiplied by the quantity $(\mathrm{Q})$.

\subsection{Analysis of returnable packaging cost}

The cost structure of a returnable packaging system is more complex compared to the disposable one.

In case of industrial, returnable packaging (operating in a closed-loop) the companies make decisions mainly based on the cost.

The calculation of the final expenses (total cost) is effected by the following components/elements:

- $\quad$ purchase price of the returnable packaging device (packaging material cost)

- cost of return transport

- cost of storage, repair and cleaning

- administration cost

- cost of disposal (waste)

- quantity of the returnable packaging devices needed to maintain the operation of the system

- number of uses

return ratio

$$
\begin{gathered}
\sum C T_{R}=P_{R} Q+P_{R} Q(1-R R)+T_{R}(U-1) Q R R+A Q+(S+R+C) Q R R+ \\
W Q,
\end{gathered}
$$

where the total cost of a returnable packaging system $\left(\mathrm{CT}_{\mathrm{R}}\right)$ is calculated from the price of the returnable packaging material $\left(\mathrm{P}_{\mathrm{R}}\right)$ squared by the quantity $(\mathrm{Q})$ initially needed for the system the operate smoothly, the price of not returning packaging devices which have to be purchased again, the cost of return transport (except for the last route at the end of the life cycle of the packaging device), furthermore the unit costs of the administration (A), storage (S), repair (R), cleaning (C) and waste (W). Return ratio (RR) is explained the next section. 


\subsection{Model criteria}

1) Relation between packaging (purchase) price and transport cost

There are two possible cases:

- the cost of a new packaging device is higher than the cost of transporting back the same packaging: $P_{R} \geq T_{R}$

- the cost of a new packaging device is lower than the cost of the reverse transportation: $\mathrm{P}_{\mathrm{R}} \leq \mathrm{T}_{\mathrm{R}}$

In our model we assume that in case of a closed loop returnable packaging system the cost of purchasing a new packaging device should be higher than the cost of back transportation, otherwise it is not economical to transport it back, because we rather buy a new one.

\section{2) Introduction of return ratio}

The return ratio (RR) represents the percentage of the packaging devices returning back from the whole pool, it has a value between $0 \%$ and $100 \%$. We assume that RR can never reach $100 \%$, because it would mean that all packaging devices come back and it is not possible in the practice.

The return ratio (Fig 3 ) is expressed as the ratio of the transport cost $\left(T_{R}\right)$ and the price of a new packaging device $\left(\mathrm{P}_{\mathrm{R}}\right)$ :

$$
R R=1-\frac{T_{R} \epsilon}{P_{R}{ }^{\epsilon}}=1-\left(\frac{T_{R}}{P_{R}}\right)^{\varepsilon},
$$

We apply an elasticity modulus $(\mathcal{E})$ in order to model real life circumstances better, because the relationship between $\mathrm{RR}$ and $\mathrm{T} / \mathrm{P}$ is non-linear. These conditions can be for example the lack of operation conditions, i.e. bad road or IT infrastructure or the low motivation level of the stakeholders of the SC, for example willingness to send back the empty packaging devices. $\mathcal{E}$ should be between 0 and $1: 0<\mathcal{E}<1$.

Because $P_{R} \geq T_{R}$ and RR should never exceed $100 \%$, the ratio of $T / P$ should be between 0 and 1 .

$$
0 \leq \frac{T_{R}}{P_{R}} \leq 1 \text { and also }\left(\frac{T_{R}}{P_{R}}\right)^{\varepsilon} \leq 1
$$




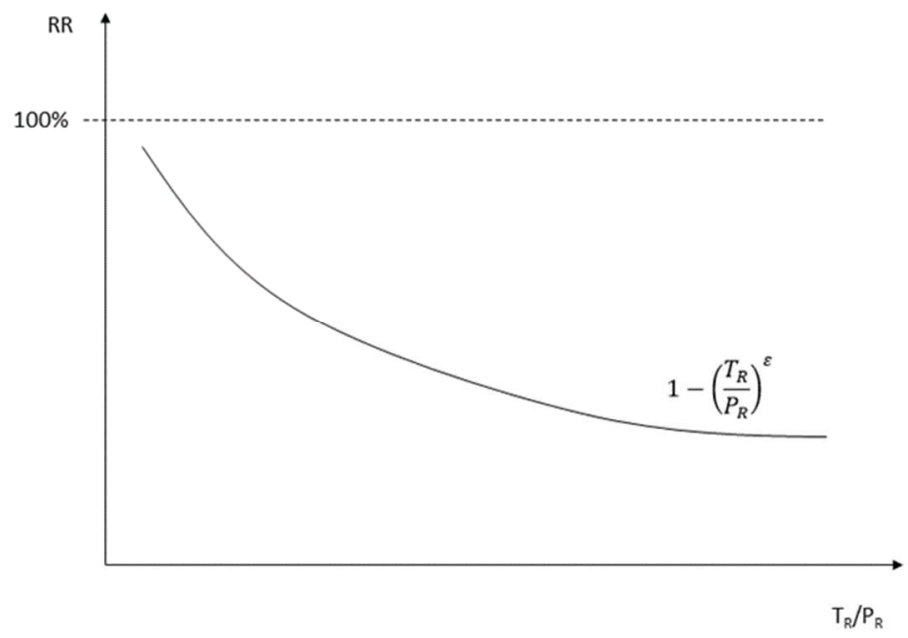

Figure 3. The effect of $T_{R} / P_{R}$ on the return ratio

If we substitute RR with the above formula, we get the following equation:

$$
\begin{gathered}
\sum C_{T}=P_{R} Q+P_{R} Q\left(1-\frac{T_{R}^{\varepsilon}}{P_{R} \varepsilon}\right)+T_{R}(U-1) Q \frac{T_{R}^{\varepsilon}}{P_{R} \varepsilon}+A Q+ \\
(S+R+C) Q \frac{T_{R}^{\varepsilon}}{P_{R}^{\varepsilon}}+W Q
\end{gathered}
$$

We are looking for the minimum value of the equation (3).

$$
\frac{d C_{T}}{d T_{R}}=-\varepsilon \frac{P_{R}}{P_{R}^{\varepsilon}} Q T_{R}^{\varepsilon-1}+\frac{\varepsilon T_{R}(U-1) Q T_{R}^{\varepsilon-1}}{P_{R}^{\varepsilon}}+\varepsilon \frac{(S+R+C) Q T_{R}^{\varepsilon-1}}{P_{R}^{\varepsilon}}=0
$$

Using the presented analytical way, we could find an optimum point. 


\section{Case study}

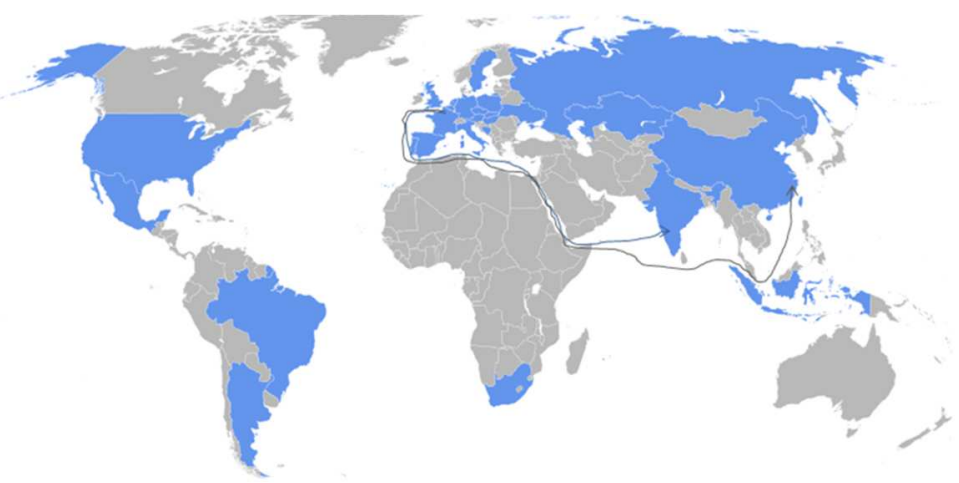

Figure 4. Transport routes to India and China

In the case overseas CKD (completely knocked down) transport will be examined. The same returnable packaging is used for automotive engine (CKD) transport from Europe to two different destinations in India and China (Fig 4). The packaging comes back from China, but it will be discarded in India. In both cases it is transported by multimodal transport, namely road, rail and sea. More than $85 \%$ of the transport distance is carried out by maritime transport and merely around $3 \%$ (India) and $1 \%$ (China) is by road.

The finished CKD engines are sensitive products therefore special racks are mainly used to store and transport them (Fig 5). These ensure safe and reliable transport and storage. The column is usually collapsible in order to save place while returning back as empty transportation. The posts are supposed to keep the engine in place, but these can be also collapsed. The returnable packaging system also contains disposable components, namely VCI (anti corrosion) foil. 

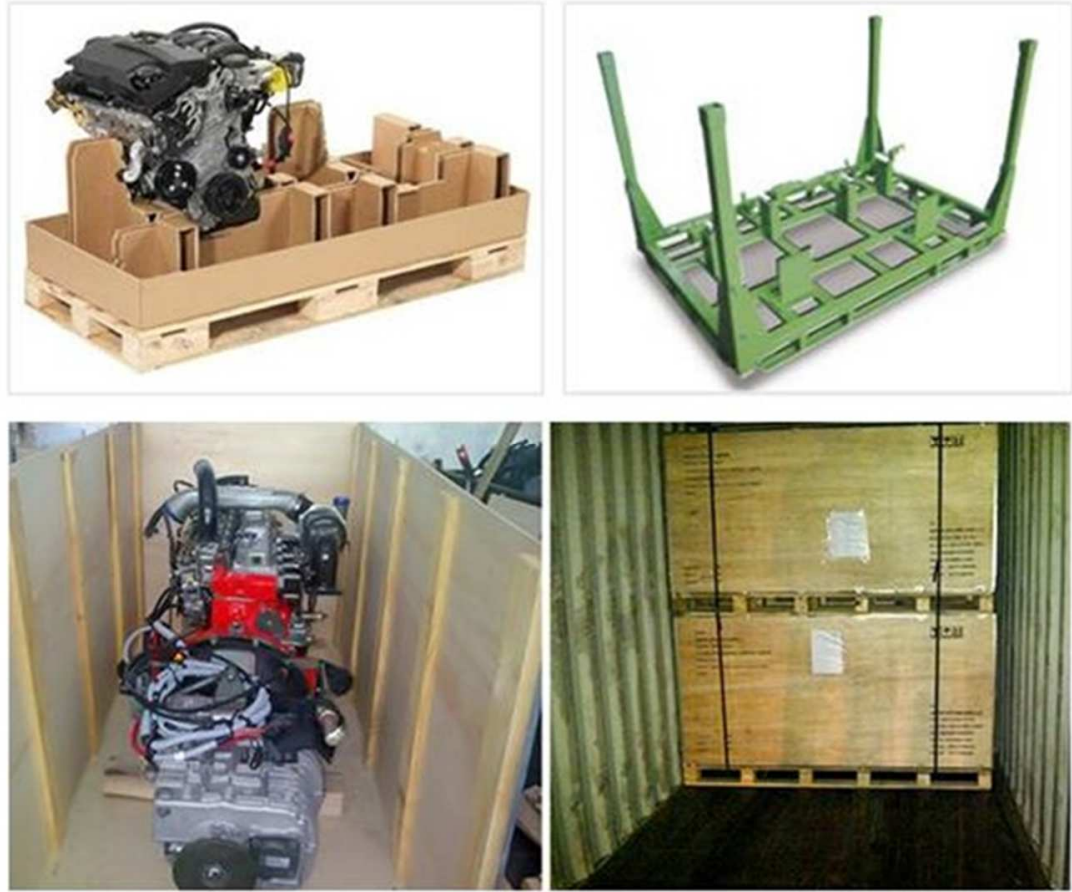

Figure 5. Examples of industrial CKD packaging [24] [25] [26]

In this case, the engine company plays the role of system integrator, then the OEM (Original Equipment Manufacturer) complies with the vehicle assembling factory. As it is shown in the case study example, returnable packaging is more common on the outbound flow of the engine companies.

\subsection{Cost calculations}

In the following section we present examples for how certain cost components included in the returnable packaging system influence the returnable packaging decision. Calculations are based on empirical data and the above described theoretical framework. The effect of variable transport cost and packaging purchase price will be highlighted in the results besides different planned number of uses. 


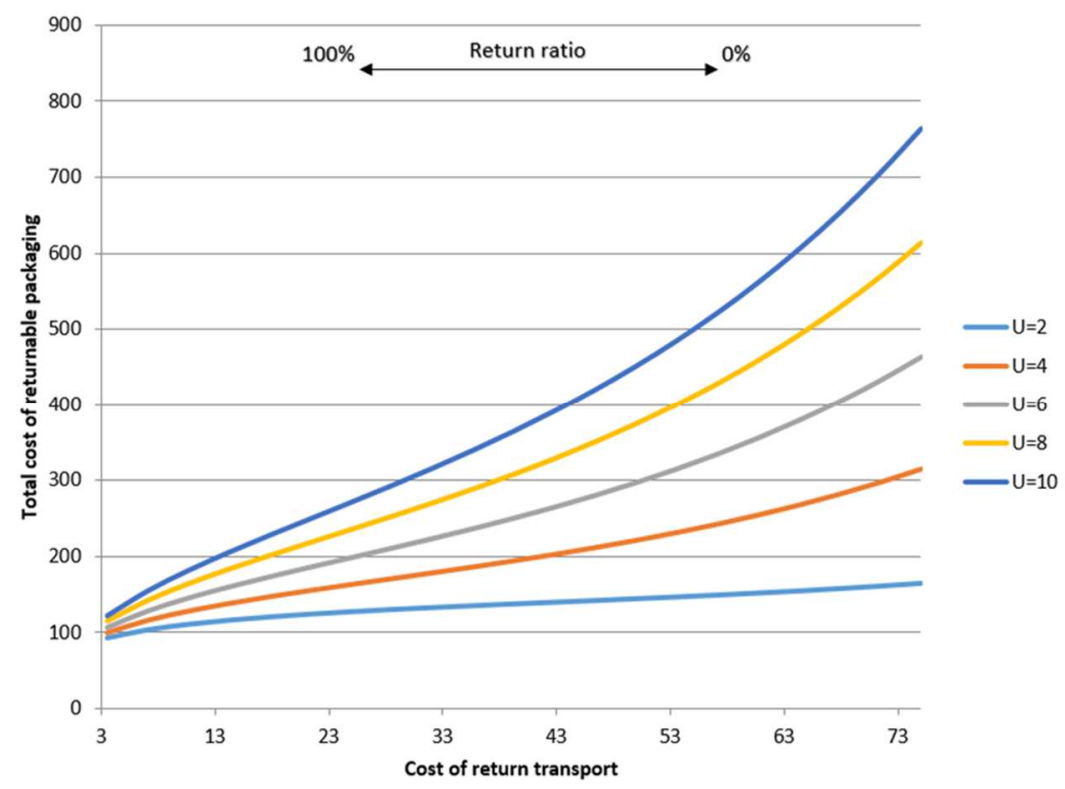

Figure 7. Total cost in case of variable transport cost and different planned usage number

In the first case (Fig 7) the price of the packaging device is fixed, €75. As it is one of the model criteria, we suppose that the return transport cost is less than the purchase price of the packaging. This is why the transport cost is only examined between $€ 1$ and $€ 75$.

The unit costs of storage, repair, cleaning administration and disposal (waste) are also fixed in the model according to the followings:

- Storage $€ 1,50$

- $\quad$ Repair (average) $€ 2,50$

- Cleaning $€ 0,20$

- Admin $€ 0,01$

- Waste $€ 10,00$

The graph shows the optimal cost besides different planned number of uses $(\mathrm{U}=2$; $4 ; 6 ; 8 ; 10)$ taking the changes of the return ratio into consideration at the same time. 
The curves present the line until it is worth it to choose returnable packaging (above the line disposable packaging should be preferred).

The model gives us a decision map in terms of how to find the appropriate technical solution besides variable transport cost, if all other data is known.

The following figure (Fig 8) illustrates an example where two solutions with the same logistics performance, but different planned usage $(U=2$ and $U=10)$ are compared. This means that the packaging device planned for two uses has to be bought 5 times. It also has to be highlighted that because of the formula the return transport cost is only included 5 times in the total cost of this case.

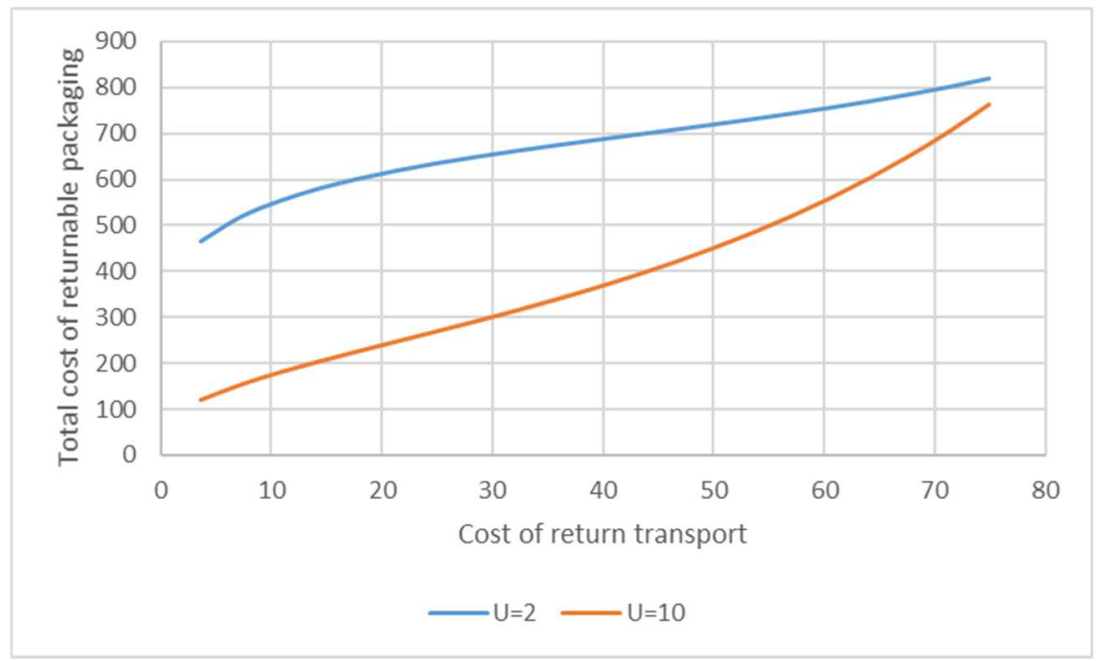

Figure 8. Comparison of total cost besides the same logistical performance

Nevertheless, if the same price is assumed for returnable packaging devices, value of the tied-up capital will be less for the solutions which can be used more times. It leads us to the conclusion that a packaging system needs to be developed which allows as many uses as possible besides acceptable price and also the stakeholders of a closed loop system need to be encouraged to return the packaging. Environmental impact is not considered in our model.

\section{Conclusion}

Automotive industry is one of the world's most significant economic sectors by its revenue. Engine transportation is carried out between different facilities all over the world. Besides waste reduction and optimal cost level, the best packaging solutions 
for automotive packaging are those that can maximize the use of packaging space so that all the products can easily be packed and stacked. Appropriate protection of the sensitive and relatively expensive products (engines) is also crucial, especially during overseas transport where the external forces are multiplied. However, managing returnable packaging systems requires more than just inverse transportation. Many other cost factors should be considered in the process.

In the case study, we assume that the price of a technically suitable packaging device is constant, that is why we optimize the model for the ways and costs of return (back) transport, in order to define the appropriate alternative so that it is economically worth it to introduce a returnable packaging system. We optimize according to this criterion in our model. Although the result is situation specific, the formula could be generalized across other industrial settings for closed-loop returnable packaging systems.

\section{Acknowledgement}

The authors would like to thank to EFOP-3.6.1-16-2016-00017 1 'Internationalisation, initiatives to establish a new source of researchers and graduates, and development of knowledge and technological transfer as instruments of intelligent specialisations at Széchenyi István University' for the support of the research.

\section{References}

[1] H. M. Gamez-Alban, , O.C. Soto-Cardona, , C. Mejia-Argueta, A. T. Sarmiento, A cost-efficient method to optimize package size in emerging markets, European Journal of Operational Research, 241 (3) (2015) pp. 917 926.

doi: $\underline{10.1016 / \text { j.ejor.2014.09.020 }}$

[2] F.T.S. Chan, H.K. Chan, K.L. Choy, A systematic approach to manufacturing packaging logistics, International Journal of Advanced Manufacturing Technology 29 (9-10) (2005) pp. 1088-1101. doi: $\underline{10.1007 / \mathrm{s} 00170-005-2609-\mathrm{x}}$

[3] C.A.S. Dominic, Towards a conceptual sustainable packaging development model: A corrugated box case study, Packaging Technology and Science, 28 (2015) pp. 397-413. doi: $10.1002 /$ pts. 2113 
[4] R. Accorsi, A. Cascini, S. Cholette, R, Manzini, C. Mora, Economic and environmental assessment of reusable plastic containers: A food catering supply chain case study, International Journal of Production Economics, 152 (2014) pp. 88-101.

doi: $10.1016 /$ j.ijpe.2013.12.014

[5] E. Svanes, M. Vold, H. Møller et al., Sustainable packaging design: a holistic methodology for packaging design. Packaging Technology and Science, 23 (3) (2010) pp. 161-175.

doi: $10.1002 /$ pts. 887

[6] Q. Zhang, A. Segerstedt, Y. C. Tsao, B. Liu, Returnable packaging management in automotive parts logistics: Dedicated mode and shared mode, International Journal of Production Economics, 168 (2015) pp. 234-244. doi: $10.1016 /$ j.ijpe.2015.07.002

[7] K. Vöröskői, P. Böröcz, Framework for the Packaging Supply Chain of an Automotive Engine Company, Acta Technica Jaurinensis, 9 (3) (2016) pp. 191-203.

doi: 10.14513 /actatechjaur.v9.n3.409

[8] What Are The Best Packaging Solutions For Automotive Packaging (2013) [cited 2016-10-05]

URL http://www.mjspackaging.com/blog/what-are-the-best-packagingsolutions-for-automotive-packaging/

[9] P. Böröcz, Á. Mojzes: The importance of packaging in logistics. Transpack, 8 (2) (2008) pp. 28-32. in Hungarian

[10] K. L. Yam: The Wiley encyclopedia of packaging technology. Wiley, USA, 2009

[11] P. Böröcz, P. Földesi: The application of the game theory onto the analysis of the decision theory of logistic packagings, Acta Technica Jaurinensis, 1 (2) (2008) pp. 259-268.

[12] H. Palsson, et al., Selection of Packaging Systems in Supply Chains from a Sustainability Perspective: The Case of Volvo, Packaging Technology and Science, 26 (2013) pp. 289-310.

doi: $\underline{10.1002 / \text { pts. } 1979}$ 
[13] P. Böröcz, S.P. Singh.: Measurement and Analysis of Vibration Levels in Rail Transport in Central Europe. Packaging Technology and Science 30 (2016) pp. 361-371.

doi: $\underline{10.1002 / \text { pts. } 2225}$

[14] C. E. Witt: Are reusable containers worth the cost? Material Handling Management, 55 (7) (2000) p.75.

[15] N. Boysen, S. Emde, M. Hoeck, M. Kauderer: Part logistics in the automotive industry: Decision problems, literature review and research agenda. European Journal of Operational Research, 242 (1) (2015) pp. 107-120. doi: $\underline{10.1016 / j . e j o r .2014 .09 .065}$

[16] C. Dominic, et al.: Förpackningslogistik. 2000: Packforsk, Kista

[17] European Commission: Packaging and Packaging Waste [cited 2017-12-09] URL http://ec.europa.eu/environment/waste/packaging/index en.htm

[18] S. G. Azevedo, H. Carvalho, V. C. Machado, The influence of green practices on supply chain performance: A case study approach, Transportation Research Part E: Logistics and Transportation Review, 47 (6) (2011) pp. 850871.

doi: $10.1016 /$ j.tre.2011.05.017

[19] A. Conte, G.M. Cappelletti, G.M. Nicoletti, C. Russo, M.A. Del Nobile: Environmental implications of food loss probability in packaging design, Food Research International, 78 (2015) pp. 11-17.

doi: $10.1016 /$ j.foodres.2015.11.015

[20] S. Ross, D. Evans, The environmental effect of reusing and recycling a plastic-based packaging system, Journal of Cleaner Production, 11 (5) (2003) pp. 561-571.

doi: $10.1016 /$ j.foodres.2015.11.015

[21] D. Twede, R. Clarke, Supply chain issues in reusable packaging. Journal of Marketing Channels, 12 (1) (2004) pp. 7-26.

doi: $\underline{10.1300 / J 049 v 12 \mathrm{n} 01 \quad 02}$

[22] D. Mollenkopf, D. Closs, D. Twede, S. Lee, G. Burgess, Assessing the viability of reusable packaging: A relative cost approach. Journal of Business 
K. Vörösköi and P. Böröcz-Acta Technica Jaurinensis, Vol. 12, No. 2, pp. 82-100, 2019

Logistics, 26 (1) (2005) pp. 169-197.

doi: $\underline{10.1002 / \mathrm{j} .2158-1592.2005 . t b 00198 . \mathrm{x}}$

[23] Industrial packaging [cited 2017-12-09]

URLhttp://www.dssmith.com/contentassets/448ba5a06897471d921313fcc43

77680/industrial packaging.jpg? $\mathrm{w}=650 \& \mathrm{~h}=340 \& \operatorname{mode}=$ max \&scale $=$ both \&fo $\underline{\text { rmat }=\text { jpg\&quality }=75}$

[24] CKD/SKD packaging [cited 2017-12-09]

URL http://flexol.in/site/wp-content/uploads/2015/09/ckdskd-4.jpg

[25] Stillage for transport of engine [cited 2016-10-03]

URL http://china-rollcontainer.com/product-6-1-engine-transport-

stillage.html/138065 